\title{
Primary Care Nurse Practitioner Wage Differences by Employment Setting
}

\author{
Yin Li, Ph.D. ${ }^{a, 1, *}$, George "Mark" Holmes, Ph.D. ${ }^{b, 2,3}$, Erin P. Fraher, Ph.D. MPP ${ }^{c, 4}$, \\ Barbara A. Mark, Ph.D., RN, FAAN ${ }^{d, 5}$, Cheryl B. Jones, Ph.D., RN, FAAN ${ }^{e, 6}$ \\ ${ }^{a}$ Research Assistant Professor, Nell Hodgson Woodruff School of Nursing, Emory University, Atlanta, GA 30322 \\ ${ }^{\mathrm{b}}$ Associate Professor, Department of Health Policy and Management, Gillings School of Global Public Health, Director of Cecil G. Sheps Center \\ for Health Services Research, University of North Carolina at Chapel Hill, Chapel Hill 27599-7411 \\ 'Assistant Professor, Department of Family Medicine, School of Medicine, Director of Program on Health and Workforce Research and Policy, \\ Cecil G. Sheps Center for Health Services Research, CB\#7590, University of North Carolina at Chapel Hill, Chapel Hill 27599-7590 \\ dSarah Frances Russell Distinguished Professor, School of Nursing, CB\#7460, University of North Carolina at Chapel Hill, Chapel Hill, \\ NC 27599-7460
}

eProfessor Director, Hillman Scholars Program in Nursing Innovation, School of Nursing, CB\#7460, University of North Carolina at Chapel Hill, Chapel Hill, NC 27599-7460

\section{A R T I C L E I N F O}

Article history:

Received 13 January 2018

Received in revised form 18 June

2018

Accepted 27 June 2018

Available online July 17, 2018.

Keywords:

Wage Difference

Nurse Practitioner

Primary Care

Specialty Care

\section{A B S T R A C T}

Background: Previous studies reported that primary care nurse practitioners working in primary care settings may earn less than those working in specialty care settings. However, few studies have examined why such wage difference exists.

Purpose: This study used human capital theory to determine the degree to which the wage differences between PCNPs working in primary care versus specialty care settings is driven by the differences in PCNPs' characteristics. Feasible generalized least squares regression was used to examine the wage differences for PCNPs working in primary care and specialty care settings.

Methods: A cross-sectional, secondary data analysis was conducted using the restricted file of 2012 National Sample Survey of Nurse Practitioners.

Findings: Oaxaca-Blinder decomposition technique was used to explore the factors contributing to wage differences.

The results suggested that hourly wages of PCNPs working in primary care settings were, on average, 7.1\% lower than PCNPs working in specialty care settings, holding PCNPs' socio-demographic, human capital, and employment characteristics constant. Approximately $4 \%$ of this wage difference was explained by PCNPs' characteristics; but $96 \%$ of these differences were due to unexplained factors.

Discussion: A large, unexplained wage difference exists between PCNPs working in primary care and specialty care settings. \footnotetext{
Atlanta, GA 30322.

E-mail address: yin.li@emory.edu (Y. Li). https://doi.org/10.1016/j.outlook.2018.06.009

${ }^{1}$ Phone: (404)-727-8445

${ }^{2}$ Voice: (919) 807-1532

${ }^{3}$ Fax: (919) 966-1634

${ }^{4}$ Phone: (919) 966-5012

${ }^{5}$ Phone: (919) 843-6209

${ }^{6}$ Phone: (919) 966-5681
}

* Corresponding author: Yin Li, Ph.D. Research Assistant Professor, Nell Hodgson Woodruff School of Nursing, Emory University, 
Cite this article: Li, Y., Holmes, G.M., Fraher, E.P., Mark, B.A., \& Jones, C.B. (2018, November/December). Primary Care Nurse Practitioner Wage Differences by Employment Setting. Nursing Outlook, 66(6), 528-538. https://doi.org/10.1016/j.outlook.2018.06.009.

\section{Introduction}

The number of primary care nurse practitioners (PCNPs) nurse practitioners (NPs) who are certified in a primary care specialty - has increased by $30 \%$ in the past decade in the United States because of the growing role they fill in providing access to primary care services (Josiah Macy Jr. Foundation, 2016; U. S. Department of Health and Human Services, 2016). Not all certified PCNPs practice in primary care settings e.g. community health centers, physician offices, school health, home health, ambulatory care clinics, and hospital outpatient departments. Instead, they often practice in specialty care and "other" settings, including hospitals, emergency departments, mental health clinics, urgent care, and long-term care (Chattopadhyay, Zangaro, \& White, 2015; Keough, Stevenson, Martinovich, Young, \& Tanabe, 2011; Spetz, Fraher, Li, \& Bates, 2015). In 2011, $75 \%$ of the U.S. supply of NPs was certified in a primary care specialty area, but only $49.0 \%$ of NPs practiced in a primary care setting (Spetz et al., 2015).

One reason that PCNPs may not work in primary care settings is that they earn lower wages working in primary care than in specialty care settings (Bodenheimer \& Bauer, 2016; Coomer, 2013; Jones \& Gates, 2004; McGregory, Niederjohn, \& Peoples, 2009; Petterson, Phillips, Bazemore, Burke, \& Koinis, 2013; Schumacher \& Hirsch, 1997; Walani, 2013). For NPs, Goolsby (2006) used the 2004 data file of the National Nurse Practitioner Sample Survey (NNPSS) conducted by the American Academy of Nurse Practitioners and reported that, regardless of certification, the average hourly wage of NPs working in primary care settings was $\$ 36.51$, considerably lower than the $\$ 39.59$ average wage for those working in specialty care settings. In a later study, Goolsby (2009) examined data from the 2008 NNPSS file and found that the average annual wage of NPs working in primary care settings was $\$ 84,771$, compared to $\$ 92,575$ for NPs working in specialty care settings.

Although previous studies have reported that wage differences exist for both RNs and NPs in primary care and specialty care settings, researchers have not examined whether such wage differences exist for PCNPs specifically or examined why wages differ for PCNPs. Lower wages for NPs (both PCNPs and NPs certified in other specialties) working in primary care settings have been associated with lower job satisfaction (Pasaron, 2013), a greater likelihood of turnover (De Milt, Fitzpatrick, \& Sister Rita, 2011), or NP graduates seeking employment outside of primary care settings (Budd, Wolf, \& Haas, 2015).

This study investigated whether wage differences exist for PCNPs who work in primary care versus specialty care settings and examined the factors contributing to these wage differences. Although such wage differences between primary care and specialty physicians have been the subject of previous studies and have been shown to affect the recruitment and retention of physicians in primary care specialties, no such study has examined potential wage differences for nurse practitioners in different settings (Heisler \& Sarata, 2011; Wilder et al., 2010). Developing a better understanding of the sources of wage differences is important to inform human resource policies and payment incentives that affect the attractiveness of primary care relative to other specialties.

\section{Conceptual Approach}

This study is grounded in human capital theory, a theory that has been widely used to examine nurses' wages and the wage differences between certain nursing groups. Human capital refers to an individual's personal characteristics (i.e., innate abilities and intelligence, acquired knowledge and education, job skills and abilities, and work experiences) or behaviors (e.g., job mobility) that affect their productivity and performance (Becker, 1962, 2009; Currie \& Madrian, 1999; Kiker, 1966; Mincer, 1958; Schultz, 1961; Willis, 1985). According to human capital theory, individuals make financial (e.g., tuition payments) and non-financial (e.g., time) investments to acquire human capital, with the expectation that they will receive a return on investment at some future point (Ehrenberg \& Smith, 2010; Schultz, 1961). Given that individuals' investments in human capital provide them knowledge, skills, and abilities that allow them to do new and/or different work, an important assumption of human capital theory is that greater human capital investments result in higher productivity (Mincer, 1958; Schultz, 1961). Because productivity per se is difficult to observe directly and measure, labor economists typically consider individuals' wages as a proxy for productivity. Human capital theory thus posits that as human capital increases, wages also increase (Becker, 2009).

Further, human capital theory acknowledges that, in addition to human capital, individuals' personal attributes can also affect their wages, including socio-demographic (e.g., gender, race, and marital status) and employment characteristics (e.g., work setting, position, geographic region, or full-time or part-time employment) (Becker, 2009, 2010). Thus, researchers typically model individuals' wages as a function of their human capital and personal attributes.

It is possible, however, that wage differences cannot be fully explained by individuals' human capital and personal attributes; instead wage differences may be attributable to other measurable and unmeasurable factors. To identify sources of wage differences, Oaxaca (1973) 
developed a widely used approach to decompose wage differences into two main effects - endowment effects and coefficient effects. Endowment effects are "explained factors" that reflect the contributions of individuals' human capital and personal attributes. For example, previous studies suggested that nurses working in specialty care settings were paid more relative to nurses in primary care settings, because they have higher cognitive ability (as measured by Armed Force Qualifying Test Scores) and greater years of experience (e.g., organizational and occupational tenure) (Schumacher \& Hirsch, 1997). Coefficient effects are "unexplained factors" that reflect factors not observed in wage modeling. For instance, researchers in previous studies speculated that nurses working in specialty care settings were paid more to compensate for unpleasant working conditions (e.g., irregular or late shifts, higher stress levels, and greater job hazards) or to cover their pension and insurance, but these factors were not examined in wage modeling due to data limitations (Lehrer, White, \& Young, 1991; Schumacher \& Hirsch, 1997).

Although there have been many applications of human capital theory for RN wage differences (Coomer, 2013; Jones \& Gates, 2004; Kalist, 2002; McGregory Jr, 2013; Spetz, 2002; Walani, 2013), there have been none of NP differences. While Goolsby $(2006,2009)$ descriptively compared the average NP wages between primary care and specialty care settings, the analysis did not model NPs' wages as a function of human capital and personal attributes. Thus, little is known about whether the wage differences between NPs working in primary care and specialty care settings exist after controlling for those factors. Although researchers have speculated about reasons for wage differences, no study has parsed differences into endowment and coefficient effects. Guided by human capital theory, this study sought to examine wage differences for PCNPs employed in primary care and specialty care settings; and explore the extent to which endowment and coefficient effects contribute to wage differences for PCNPs working in primary care and specialty care settings. A deeper understanding of the source of any wage differences may enable policy makers and employers to make adjustments necessary to support a more efficient market.

\section{Methods}

\section{Design}

This study used a secondary analysis of cross-sectional data, extracted from the restricted file of the Department of Health and Human Services, Health Resources and Services Administration (HRSA) National Sample Survey of Nurse Practitioners (NSSNP) 2012. Data gathered in this survey were obtained from a stratified sample of 22,000 actively licensed or certified U.S. NPs. ${ }^{1}$ The survey

\footnotetext{
${ }^{1}$ The NSSNP only surveyed NPs; employers were not included as part of the survey.
}

achieved a response rate of approximately $60 \%$, for a final sample of 12,923 NPs. Data gathered in this survey included NP demographic, socioeconomic, educational, certification, employment, and practice characteristics (U.S. Department of Health and Human Services, 2014).

\section{Sample}

The sample for this study included NSSNP respondents who met the following inclusion criteria: 1) practice approval obtained through a state board of nursing; 2) certified as a PCNP, in one of the following primary care specialty areas - adult, family, geriatric, pediatric, or women's health ${ }^{2}$; 3) worked for pay as an NP; and 4) practiced in a primary care or specialty care setting in their principal NP job. Based on the categorization of NPs' working setting in NSSNP 2012, a primary care setting in this study was defined as private physician office, private NP office, nurse managed clinic, retail clinic, ambulatory care, federal clinic, home care agency, community clinic, correctional facility, health department, rural health clinic, health maintenance organization, employee health, and school health; specialty care settings were defined as mental health center, urgent care clinic, hospital inpatient unit, hospital outpatient, hospital emergency department, other hospital settings, federal hospital (Military, Veteran Affairs, India Health Services), hospital surgical settings, hospital other clinic settings, and hospital non-clinical settings. ${ }^{3}$

After applying these initial inclusion criteria, the sample was 8,175. Of these, 1,829 NPs responded "not applicable" or "unknown" on relevant study variables. Observations for these NPs were dropped or imputed for analysis, leaving 7,532 observations as the final sample used in this study. ${ }^{4}$ This PCNP final sample consisted of $5,793(76.9 \%)$ observations in primary care settings and 1,739 (23.1\%) observations in specialty care settings.

\section{Wage Models and Variables}

Based on human capital theory and Mincer's wage model (Mincer, 1974), PCNP wages were modeled as a function of PCNPs' socio-demographic, human capital, and employment characteristics of the general form:

\footnotetext{
${ }^{2}$ In the final sample, 792 (10.5\%) out of the 7,532 observations hold more than one certification. Based on human capital theory, an NP holding more certifications may earn higher wages. Therefore, a binary variable of whether a PCNP holding multiple certifications $(0=$ only one certification; and $1=$ more than one certification) was created and included in a preliminary wage modeling analysis. Because this variable was not statistically significant associated with wages, however, it was not included in our final wage modeling.

${ }^{3}$ These types of settings were not mutually exclusive, but they were directly derived from the NSSNP 2012. The categorization of primary care and specialty care settings were based on the study of Spetz, Fraher, Li, and Bates (2015).

${ }^{4}$ Data were dropped if missing data were less than or equal to $5 \%$ and imputed if greater than $5 \%$ of the 8,175 observations. Information on the management of missing data can be obtained from the corresponding author.
} 
Wage $=f(S, H, E, e)$

Where

Wage is the hourly PCNP wage, which was calculated by using the pre-tax annual earnings from the principal NP position (include overtime, on call earning, and bonuses) in 2011 divided by the product of the number of hours worked in the principal NP position during a typical week times 52 weeks;

$S$ is a vector of PCNP socio-demographic characteristics, including gender (male or female), race (white or non-white), ethnicity (Hispanic or non-Hispanic), and marital status (never married, married, or separated, divorced, widowed, and other);

$H$ is a vector of PCNP human capital characteristics, including NP education preparation (certificate program, Master's degree, Post Master's degree, or Doctor of Nursing Practice degree and other), years of NP experience (2011 minus the year of completing the initial NP education program), and intent to leave their position (no plan to leave, leave in 2012, leave in 1-2 years, or undecided or unknown);

$E$ is a vector of PCNP employment characteristics, including type of their employment setting (primary or specialty care), type of their position (NP position in a clinic, other position that requiring NP credentialing, other position that not requiring NP credentialing, or other nursing position ${ }^{5}$ ), specialty of their practice clinic (primary or specialty care $^{6}$ ), degree of their practice independence (no physician on site, worked with a physician as a team member, supervised by a physician or other relationships with a physician), Metropolitan

\footnotetext{
${ }^{5}$ These types of positions are mutually exclusive; also, the survey did not ask if a NP held multiple positions. All of the types of positions were included in the final analysis because it is possible that PCNPs could work in a position that does not require NP credentialing, e.g., NPs working in a hospital can work in a RN staff position but still hold a NP certification. The percentage of this group of NPs is very small in our sample (3\%), which did not significantly affect the analysis and results.

${ }^{6}$ Because NPs work in a primary care settings may not practice in a primary care specialty. For example, for a NP working in a cardiologist office, she/he works in a primary care settings but practice in a specialty care specialty. Primary care specialty refers to internal medicine, family practice, geriatrics, general pediatrics, OB/GYN women's health, and school health. Specialty care specialty refers to pediatric subspecialties, adolescent medicine, cardiology, endocrinology, gastroenterology, hematology/oncology, infectious disease, pulmonary/respiratory, renal/nephrology, rheumatology, general surgery, urology, orthopedics, other surgical specialties, allergy \& immunology, dermatology, emergency care, hospitalist, intensive care, neonatal, neurology, occupational health, palliative care/pain management, psychiatry/mental health, rehabilitation, urgent care, wound/ostomy, and surgical (anesthesia, cardio, cardiothoracic, vascular, thoracic, neurological, radiology).
}

Statistical Areas [MSA] region of employment (urban [ $>=50,000$ population], large rural $[10,000-$ 49,000 population], small rural $[2,500-9,999$ population], or isolated $[<2,500$ population]), census region of employment (New England, Middle Atlantic, East North Central, West North Central, South Atlantic, East South Central, West South Central, Mountain or Pacific), salary method (paid by annual salary, by the hour, by percentage of billing, or others), and whether holding more than one RN or NP job; and e is random error.

\section{Analysis}

The following analytic model was estimated to examine PCNP wages and determine if there were wage differences for PCNPs in primary care and specialty care settings:

$\ln ($ Wage $)=\alpha+\beta_{1} X_{1}+\beta_{2} X_{2}+\beta_{3} X_{3}+\ldots+\varepsilon$

where $\ln$ (wage) is the natural logarithm of hourly PCNP wages; $\alpha$ is the constant; $\beta_{\mathrm{i}(\mathrm{i}=1,2,3 \ldots)}$ is the coefficient of each variable $X_{i(i=1,2,3 \ldots)} ; X_{i(i=1,2,3 \ldots)}$ represents the socio-demographic, human capital, and employment variables; and $\varepsilon$ is random error.

Feasible generalized least squares (FGLS) regression was used to estimate the model to overcome problems with heteroskedasticity in the data. Because statistically significant results were found, a Chow-test was used to further examine whether the "setting" variable had different effects on PCNPs in primary care and specialty care settings. To estimate the Chow test, two separate models for PCNPs - one for those in primary care and another for those in specialty care settings - were estimated using FGLS in the same format as model (2). The Chow test determined that there were structural differences between these two models $(F=2.02, p<0.01)$. This finding suggested that use of the wage decomposition approach was appropriate. Using these two models, we also predicted the average weighted level wage differences between PCNPs in primary care and specialty care settings.

Then we decomposed PCNP wages to determine the origin of differences using the technique developed by Oaxaca (1973), and later refined by others (Cotton, 1988; Holtmann \& Idson, 1993; Reimers, 1983). We followed Cotton's model (1988) and used weighted $X_{i}$ and $\beta_{i}$ terms because we used FGLS regression models to examine PCNP wages, which predicted weighted $X_{i}$ and $\beta_{i}$ :

$$
\begin{aligned}
E\left(Y_{i}^{p c w}\right)-E\left(Y_{i}^{s p w}\right)= & 0.5 \Sigma\left(\beta_{i}^{p c w}+\beta_{i}^{s p w}\right)\left(X_{i}^{p c w}-X_{i}^{s p w}\right) \\
& +0.5 \Sigma\left(X_{i}^{p c w}+X_{i}^{s p w}\right)\left(\beta_{i}^{p c w}-\beta_{i}^{s p w}\right)
\end{aligned}
$$

Where $E\left(Y_{i}^{p c w}\right)-E\left(Y_{i}^{s p w}\right)$ refers to the total effects, or the predicted weighted logged wage differences, which is the sum of endowment effects and coefficient effects; 
$0.5 \Sigma\left(\beta_{i}^{p c w}+\beta_{i}^{s p w}\right)\left(X_{i}^{p c w}-X_{i}^{s p w}\right)$ refers to the endowment effects, indicating how much the wages of PCNPs in specialty care settings would change if their weighted characteristics, $X_{i}^{s p w}$, were exactly the same as those of PCNPs in primary care settings,

$X_{i}^{p c w} ; 0.5 \Sigma\left(X_{i}^{p c w}+X_{i}^{s p w}\right)\left(\beta_{i}^{p c w}-\beta_{i}^{s p w}\right)$ refers to the coefficient effects, indicating how much the wages of PCNPs in specialty care settings would change if the coefficient, $\beta_{i}^{\text {spw }}$, representing each of their characteristics was exactly the same as those of PCNPs in primary care settings, $\beta_{i}^{p c w}$. This wage decomposition technique determined the extent to which endowment effects and coefficient effects contributed to the wage differences.

\section{Findings}

Descriptive statistics for the full PCNP sample and the two subsamples of PCNPs in primary care and specialty care settings are shown in Table 1 . T-tests and Chi-square tests were used to compare the two subsamples of PCNPs. The unadjusted average wage for PCNPs in primary care and specialty care settings were $\$ 43.7$ and $\$ 47.2$, respectively, indicating that PCNPs in primary care on average earned $8 \%$ less than those in specialty care settings. Compared with PCNPs working in specialty care settings, PCNPs who worked in primary care settings were: older, female, white, and married; had a lower level of education, more years of experience; and had no plans to leave their current position; worked as a NP, worked in a clinic that focused on a primary care specialty, practiced independently, practiced in a rural or isolated area, were paid an annual salary (versus hourly wage), and held more than one job.

\section{Wage differences between primary care and specialty care settings}

Because we assumed that the effects of PCNPs' working setting on wages would differ between PCNPs in primary care and specialty care settings, we conducted the FGLS analysis for models of the full sample and for separate models of PCNPs in primary care and specialty care settings. Findings for each statistically significant variable are presented below. ${ }^{7}$

\section{Setting}

The results for the full PCNP sample indicate that the wages of PCNPs in primary care settings were, on average, $7.1 \%$ lower $\left(=100^{*}(\exp (-0.074)-1)\right)$ than those of PCNPs in specialty care settings, holding socio-demographic, human capital, and employment characteristics constant.

\footnotetext{
7 Detailed information of the regression models and results can be obtained from the corresponding author.
}

Socio-demographics

For the full PCNP sample and two subsamples, male PCNPs earned more than females. For PCNPs in specialty care settings, PCNPs who were nonwhite earned more than white PCNPs. For the full PCNP sample, PCNPs who had never married earned less than those PCNPs who were married.

\section{Human Capital}

For the full PCNP sample and PCNPs in primary care settings, PCNPs prepared in a NP certificate program earned less than PCNPs with a master's degree.

Years of experience had a significant positive association with PCNP wages for both the full PCNP sample and the two PCNP subsamples. Figure 1 illustrates wage-experience curves for PCNPs in primary care and specialty care settings. The curves were estimated using the average predicted wage for each PCNP given his/her years of experience. PCNPs in primary care settings earned, on average, $\$ 39.66 /$ hour in their first year as a NP. Early in their career, each additional year of experience led to a wage increase of approximately $1.6 \%$. Because of the nonlinear relationship between PCNP experience and wage, the wage effect diminishes gradually as experience increases, reaching a point near 20 years of experience where wages begin to decrease with further increases in experience. The maximum wage predicted, $\$ 46.26$, is approximately $16.6 \%$ higher than entry-level wages.

The wage-experience curve for PCNPs in specialty care settings is different than that of PCNPs in primary care settings. The average entry-level wage for PCNPs in specialty care settings was $\$ 42.74 /$ hour, which was $7.8 \%$ higher than that of PCNPs in primary care settings. Early in their careers, each additional year of experience led to a wage increase of approximately $1.4 \%$, similar to the increase for PCNPs in primary care settings. The wages of PCNPs in specialty care settings also peaked near 20 years of experience at the wage of $\$ 49.85$ /hour, which was $16.6 \%$ higher than their entrylevel wage. Given their higher entry-level wages and a similar rate increase as those of PCNPs in primary care settings, the peak wage for PCNPs in specialty care settings was $7.8 \%$ higher than that of PCNPs in primary care settings.

For the full sample and the subsample of PCNPs primary care settings, PCNPs who intended to leave their jobs in the 1 to 2 years following the survey administration earned less than those who did not. However, this relationship did not hold for PCNPs working in specialty care settings.

\section{Employment}

For all samples, PCNPs employed in RN staff positions earned less than PCNPs employed in NP positions in clinical practice; and PCNPs who worked in clinics focused on primary care earned less than PCNPs working in clinics focused on specialty care.

For the full sample and the subsample of PCNPs in primary care settings, PCNPs supervised by physicians 
Table 1 - Descriptive Statistics of PGNP Sample.

Variables

Mean (SD) / n (\%)

\begin{tabular}{|c|c|c|c|c|}
\hline & $\begin{array}{l}\text { Full PCNP } \\
\text { Sample }(n=7,532)\end{array}$ & $\begin{array}{l}\text { PCNPs in } \\
\text { Primary Care } \\
\text { Setting }(n=5,793,76.9 \%)\end{array}$ & $\begin{array}{l}\text { PCNPs in Specialty } \\
\text { Care Settings } \\
(n=1,739,23.1 \%)\end{array}$ & $\mathrm{p}$-Value \\
\hline \multicolumn{5}{|l|}{ Dependent Variable } \\
\hline \multicolumn{5}{|l|}{ Independent Variable } \\
\hline \multicolumn{5}{|l|}{ Socio-demographic Characteristics } \\
\hline $\begin{array}{l}\text { Age } \\
\text { Gender }\end{array}$ & $47.1(10.8)$ & $47.4(10.9)$ & $45.9(10.6)$ & $0.00^{*}$ \\
\hline Female & $7,042(93.5 \%)$ & $5,469(94.4 \%)$ & $1,573(90.5 \%)$ & $0.00^{*}$ \\
\hline Male & $490(6.5 \%)$ & $324(5.6 \%)$ & $166(9.5 \%)$ & $0.00^{*}$ \\
\hline \multicolumn{5}{|l|}{ Race } \\
\hline White & $6,630(88.0 \%)$ & $5,146(88.8 \%)$ & $1,484(85.3 \%)$ & $0.00^{*}$ \\
\hline Non-white & $902(12.0 \%)$ & $647(11.2 \%)$ & $255(14.7 \%)$ & $0.00^{*}$ \\
\hline \multicolumn{5}{|l|}{ Ethnicity } \\
\hline Hispanic & $263(3.5 \%)$ & $193(3.3 \%)$ & $70(4.0 \%)$ & 0.17 \\
\hline Non-Hispanic & $7,269(96.5 \%)$ & $5,600(96.7 \%)$ & $1,669(96.0 \%)$ & 0.17 \\
\hline \multicolumn{5}{|l|}{ Marital Status } \\
\hline Never married & $752(10.0 \%)$ & $533(9.2 \%)$ & $219(12.6 \%)$ & $0.00^{*}$ \\
\hline Married & $5,531(73.4 \%)$ & $4,333(74.8 \%)$ & $1,198(68.9 \%)$ & $0.00^{*}$ \\
\hline Separated, divorced, widowed, and other & $1,249(16.6 \%)$ & $927(16.0 \%)$ & $322(18.5 \%)$ & $0.01^{*}$ \\
\hline \multicolumn{5}{|l|}{ Human Capital Characteristics } \\
\hline \multicolumn{5}{|l|}{ Education level } \\
\hline Certificate & $494(6.6 \%)$ & $443(7.6 \%)$ & $51(2.9 \%)$ & $0.00^{*}$ \\
\hline Master & $5,963(79.2 \%)$ & $4,559(78.7 \%)$ & $1,404(80.7 \%)$ & 0.07 \\
\hline Post master & $942(12.5 \%)$ & $692(11.9 \%)$ & $250(14.4 \%)$ & $0.01^{*}$ \\
\hline DNP or other & $133(1.8 \%)$ & $99(1.7 \%)$ & $34(2.0 \%)$ & 0.49 \\
\hline Experience of working as a NP & $8.3(10.5)$ & $11(8.6)$ & $8.81(7.12)$ & $0.00^{*}$ \\
\hline \multicolumn{5}{|l|}{ Intent to Turnover } \\
\hline No plans to leave & $5,062(67.2 \%)$ & $3,933(67.9 \%)$ & $1,129(64.9 \%)$ & $0.02^{*}$ \\
\hline Leave in 2012 & $483(6.4 \%)$ & $360(6.2 \%)$ & $123(7.1 \%)$ & 0.2 \\
\hline Leave in next $1-2$ years & $958(12.7 \%)$ & $716(12.4 \%)$ & $242(13.9 \%)$ & 0.09 \\
\hline Undecided or unknown & $1,029(13.7 \%)$ & $784(13.5 \%)$ & 245 (14.1\%) & 0.56 \\
\hline \multicolumn{5}{|l|}{ Employment Characteristics } \\
\hline \multicolumn{5}{|l|}{ Position } \\
\hline NP in clinic & $6,781(90.0 \%)$ & $5,376(92.8 \%)$ & $1,405(80.8 \%)$ & $0.00^{*}$ \\
\hline Other NP position & $171(2.3 \%)$ & $126(2.2 \%)$ & $45(2.6 \%)$ & 0.31 \\
\hline Staff & $254(3.4 \%)$ & $94(1.6 \%)$ & $160(9.2 \%)$ & $0.00^{*}$ \\
\hline Other non-NP position & $326(4.3 \%)$ & $197(3.4 \%)$ & $129(7.4 \%)$ & $0.00^{*}$ \\
\hline \multicolumn{5}{|l|}{ Specialty of Clinics ${ }^{\mathrm{b}}$} \\
\hline Primary care specialty & $3,849(51.1 \%)$ & $3,582(61.8 \%)$ & 267 (15.4\%) & $0.00^{*}$ \\
\hline Specialty care specialty & $3,004(39.9 \%)$ & $1,785(30.8 \%)$ & $1,219(70.1 \%)$ & $0.00^{*}$ \\
\hline Other, or no specialty & $679(9.0 \%)$ & $426(7.4 \%)$ & $253(14.5 \%)$ & $0.00^{*}$ \\
\hline \multicolumn{5}{|l|}{ Relationship with physician } \\
\hline Independent & 785 (10.4\%) & $727(12.5 \%)$ & $58(3.3 \%)$ & $0.00^{*}$ \\
\hline Collaborate with a physician & $5,186(68.9 \%)$ & $4,162(71.8 \%)$ & $1,024(58.9 \%)$ & $0.00^{*}$ \\
\hline Supervised by a physician & $958(12.7 \%)$ & $539(9.3 \%)$ & $419(24.1 \%)$ & $0.00^{*}$ \\
\hline Other relationship & $603(8.0 \%)$ & $365(6.3 \%)$ & $238(13.7 \%)$ & $0.00^{*}$ \\
\hline \multicolumn{5}{|l|}{ MSA Region } \\
\hline Urban & $5,998(79.6 \%)$ & $4,530(78.2 \%)$ & $1,468(84.4 \%)$ & $0.00^{*}$ \\
\hline Large rural & $667(8.9 \%)$ & $560(9.7 \%)$ & $107(6.2 \%)$ & $0.00^{*}$ \\
\hline Small rural & $302(4.0 \%)$ & $264(4.6 \%)$ & $38(2.2 \%)$ & $0.00^{*}$ \\
\hline Isolated & $191(2.5 \%)$ & $173(3.0 \%)$ & $18(1.0 \%)$ & $0.00^{*}$ \\
\hline Unknown & $374(5.0 \%)$ & $266(4.6 \%)$ & $108(6.2 \%)$ & $0.01^{*}$ \\
\hline \multicolumn{5}{|l|}{ Census Region } \\
\hline New England & $569(7.6 \%)$ & $467(8.1 \%)$ & $102(5.9 \%)$ & $0.00^{*}$ \\
\hline Middle Atlantic & $966(12.8 \%)$ & $667(11.5 \%)$ & $299(17.2 \%)$ & $0.00^{*}$ \\
\hline East North Central & $1,000(13.3 \%)$ & $765(13.2 \%)$ & $235(13.5 \%)$ & 0.74 \\
\hline West North Central & $569(7.6 \%)$ & $422(7.3 \%)$ & $147(8.5 \%)$ & 0.11 \\
\hline South Atlantic & $1,405(18.7 \%)$ & $1,061(18.3 \%)$ & $344(19.8 \%)$ & 0.17 \\
\hline East South Central & $562(7.5 \%)$ & $447(7.7 \%)$ & $115(6.6 \%)$ & 0.13 \\
\hline West South Central & $631(8.4 \%)$ & $517(8.9 \%)$ & $114(6.6 \%)$ & $0.00^{*}$ \\
\hline Mountain & $500(6.6 \%)$ & $421(7.3 \%)$ & $79(4.5 \%)$ & $0.00^{*}$ \\
\hline Pacific & $956(12.7 \%)$ & $760(13.1 \%)$ & $196(11.3 \%)$ & $0.04^{*}$ \\
\hline
\end{tabular}


Table 1 - (Continued)

\begin{tabular}{|c|c|c|c|c|}
\hline \multirow[t]{2}{*}{ Variables } & \multicolumn{3}{|c|}{ Mean (SD) / n (\%) } & \multirow[b]{2}{*}{$\mathrm{p}$-Value } \\
\hline & $\begin{array}{l}\text { Full PCNP } \\
\text { Sample }(\mathrm{n}=7,532)\end{array}$ & $\begin{array}{l}\text { PCNPs in } \\
\text { Primary Care } \\
\text { Setting }(n=5,793,76.9 \%)\end{array}$ & $\begin{array}{l}\text { PCNPs in Specialty } \\
\text { Care Settings } \\
(n=1,739,23.1 \%)\end{array}$ & \\
\hline Unknown & $374(5.0 \%)$ & $266(4.6 \%)$ & $108(6.2 \%)$ & $0.01^{*}$ \\
\hline How PCNPs are paid & & & & \\
\hline Annual salary & $4,488(59.6 \%)$ & $3,524(60.8 \%)$ & $964(55.4 \%)$ & $0.00^{*}$ \\
\hline By the hour & $2,076(27.6 \%)$ & $1,568(27.1 \%)$ & $508(29.2 \%)$ & 0.08 \\
\hline Percentage of billing & $266(3.5 \%)$ & $246(4.2 \%)$ & $20(1.2 \%)$ & $0.00^{*}$ \\
\hline $\begin{array}{l}\text { Other, or percent billing plus salary/hourly } \\
\text { Hold more than one position }\end{array}$ & $702(9.3 \%)$ & $455(7.9 \%)$ & $247(14.2 \%)$ & $0.00^{*}$ \\
\hline No & 5,784 (76.8\%) & 4,549 (78.5\%) & 1,235 (71.0\%) & $0.00^{*}$ \\
\hline Yes & $1,748(23.2 \%)$ & $1,244(21.5 \%)$ & $504(29.0 \%)$ & $0.00^{*}$ \\
\hline \multicolumn{5}{|c|}{$\begin{array}{l}\text { * Significant at the level of } \mathrm{p}<0.05 \text {. } \\
\text { a Previous researchers have suggested recoding wage values that are less than } \$ 5 \text { or greater than } \$ 100 \text { as exactly } \$ 5 \text { or } \$ 100 \text {, } \\
\text { respectively (Jones \& Gates, } 2004 \text { ). Because the wage calculation used in this study may yield some values that are not meaning- } \\
\text { ful estimations, the wages of } 56 \text { observations ( } 2.0 \% \text { of the sample) were recoded as } \$ 5 \text { or } \$ 100 \text {. Eight wage estimations were } \\
\text { recoded as } \$ 5 \text { and } 48 \text { estimations were recoded as } \$ 100 \text {. Wages ranged from } \$ 0.01 \text { to } \$ 721.15 \text {. } \\
\text { b Clinics with a primary care specialty refer to those focus on internal medicine, family practice, geriatrics, general pediatrics, } \\
\text { OB/GYN women's health, and school health. Clinics with specialty care specialty refer to those focus on pediatric subspecialties, } \\
\text { adolescent medicine, cardiology, endocrinology, gastroenterology, hematology/oncology, infectious disease, pulmonary/respira- } \\
\text { tory, renal/nephrology, rheumatology, general surgery, urology, orthopedics, other surgical specialties, allergy \& immunology, } \\
\text { dermatology, emergency care, hospitalist, intensive care, neonatal, neurology, occupational health, palliative care/pain manage- } \\
\text { ment, psychiatry/mental health, rehabilitation, urgent care, wound/ostomy, and surgical (anesthesia, cardio, cardiothoracic, } \\
\text { vascular, thoracic, neurological, radiology). }\end{array}$} \\
\hline
\end{tabular}

earned less than PCNPs who practiced independently. However, this relationship did not hold for PCNPs in specialty care settings.

For PCNPs in specialty care settings, PCNPs in large rural areas earned 6.5\% less than those in urban areas. For the full sample and the subsample of PCNPs in primary care settings, PCNPs employed in all regions earned more than those employed in the South Atlantic region, except PCNPs working in the West North Central and East South Central regions. For PCNPs in specialty care settings, those employed in New England, Middle Atlantic, West South Central, and Pacific regions earned more than PCNPs employed in the South Atlantic region.

For the full sample and the two subsamples, PCNPs who were paid on an hourly basis earned more than those who were paid an annual salary. For the full sample and the subsample of PCNPs in primary care settings, PCNPs who held more than one NP or RN position earned more than PCNPs who did not. However, this relationship did not hold for PCNPs in specialty care settings.

\section{Predicted Wages Differences}

The average predicted weighted wages for PCNPs in primary care and specialty care settings were $\$ 43.80 /$ hour and $\$ 47.93 /$ hour, respectively. The total wage difference was $\$ 4.13$, indicating that PCNPs in primary care settings earned $9.4 \%$ less than those in specialty care settings.

\section{Sources of Wage Differences}

Recall that we used a wage decomposition technique and decomposed the wage differences into two components - the "endowment" effect - the effect due to differences in PCNPs' characteristics - and the "coefficient" effects. ${ }^{8}$ The total effects were -0.1117 , indicating the wages of PCNPs in primary care settings were $10.6 \%$ lower (100* [exp $(-0.1117)-1])$ than the wages of PCNPs working in specialty care settings. The endowment effects were estimated to be -0.0045 , which explained $4 \%$ of the total wage differences. That is, PCNPs in specialty care settings would earn $0.45 \%$ less $\left(100^{*}[\exp (-0.0045)-1]\right)$ if their socio-demographic, human capital, and employment characteristics were exactly the same as those of PCNPs working in primary care settings. PCNPs in primary care settings had greater endowments than PCNPs in specialty care settings for some characteristics that are associated with higher wages (i.e., PCNPs had more experience, and fewer worked in staff positions). Specifically, if PCNPs in specialty care settings had the same years of experience or the same percent of PCNPs worked in a staff position as those working in primary care settings, their wages would increase approximately $2.2 \%$ or $1.2 \%$, respectively. However, PCNPs in primary care settings also possessed fewer endowments for some other characteristics that were also associated with lower wages, such as fewer PCNPs were male, fewer PCNPs worked in a specialty care clinic, and fewer PCNPs held more than one job. If the same percent of PCNPs in specialty care settings were male, worked in a specialty care clinic, or held more than one job, their wages would decrease about $0.4 \%, 1.7 \%$, or $0.3 \%$, respectively.

The coefficient effects were -0.1073 , which explained $96 \%$ of the total wage differences. That is, PCNPs in specialty care settings would earn $10.2 \%$ less $\left(100^{*}\right.$ [exp

\footnotetext{
${ }^{8}$ Detailed information of this wage decomposition model and results can be obtained from the corresponding author.
} 


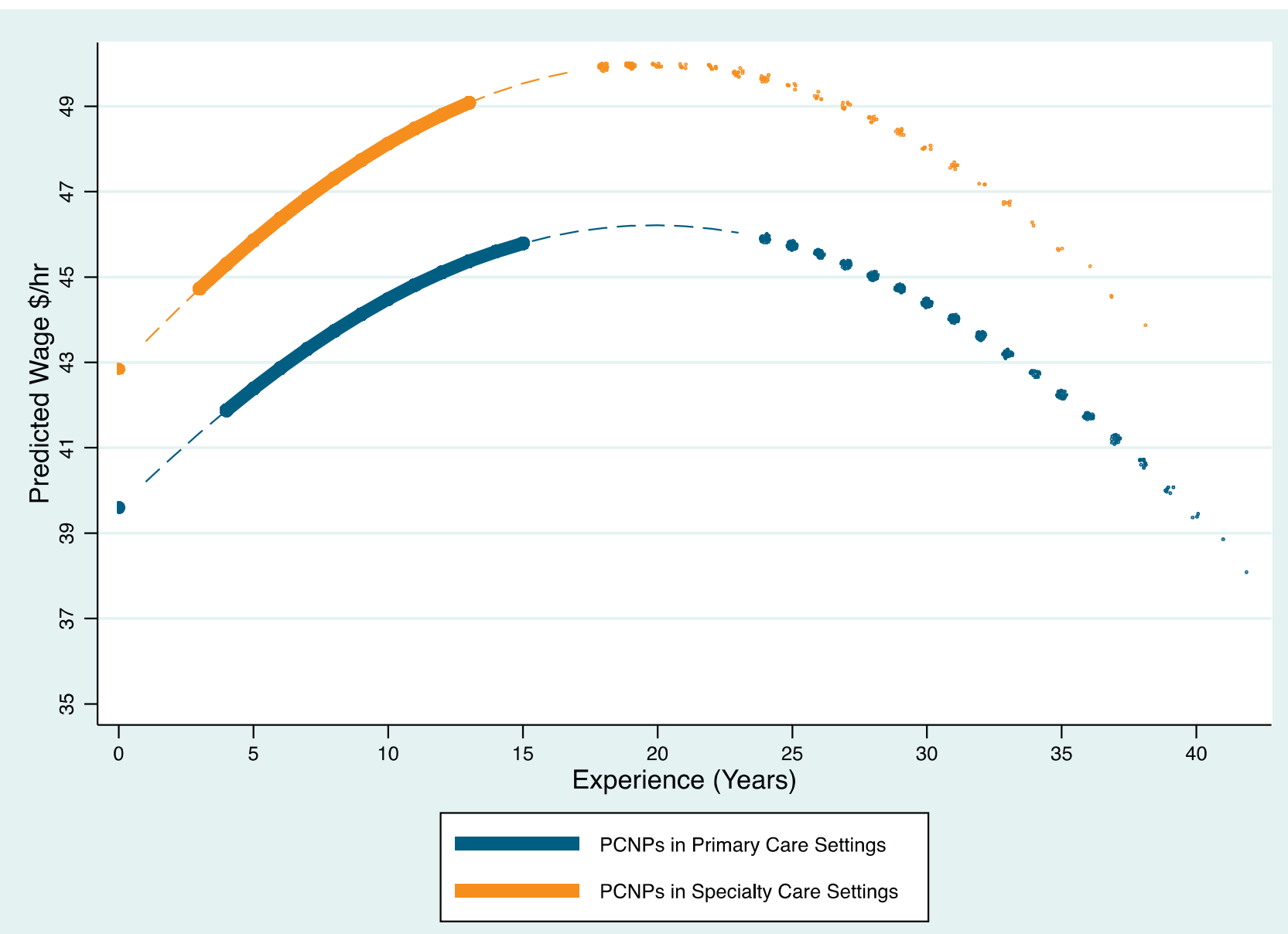

Figure 1-Wage-experience profiles for PCNPs working in primary care settings and those working in specialty care settings. The lines indicate whether the experience was within the 25th-75th percentiles (solid and thicker lines), 10th-90th percentiles (dashed lines), or above the 90th percentiles (dots). For PCNPs working in primary care settings, about $25 \%$ to $75 \%$ had 4 to 15 years of experience and had expected wages between $\$ 41.94 /$ hour and $\$ 45.83$ /hour. For PCNPs working in specialty care settings, approximately $25 \%$ to $75 \%$ had 3 to 13 years of experience and earned wages between $\$ 44.62 /$ hour and $\$ 49.94 /$ hour. Note: Wages were the average prediction, using the Duan's smearing estimators, for each subsample of PCNPs.

$(-0.1073)-1])$ if the coefficients for their socio-demographic, human capital, and employment characteristics were exactly the same as those of PCNPs in primary care settings. These effects were mainly due to the variable of PCNPs' independent practice. Specifically, PCNPs who worked in primary care settings and were supervised by a physician earned, on average, less than those working independently; however this relationship was not statistically significant for PCNPs in specialty care settings (as discussed early). If PCNPs in specialty care settings had the same coefficients of PCNPs' independence of practice as PCNPs in primary care settings, their wages would decrease $7.0 \%$.

\section{Discussion}

This study found that PCNPs in primary care settings earned significantly less than PCNPs in specialty care settings, and most of these wage differences could not be explained by endowment effects, i.e., PCNPs' human capital and personal attributes. PCNPs in primary care and specialty care settings possessed different endowments, but these differences did not significantly contribute to wage differences for these two groups. An explanation for this finding is that, although PCNPs in primary care possessed greater human capital endowments (e.g., more years of experience) than PCNPs in specialty care, they possessed other characteristics that are known to be associated with lower wages, such as being predominantly female, and working only one job, which effectively offset any potential wage gains (Jones \& Gates, 2004; Kalist, 2002). In fact, differences in total endowment effects were small for these two groups.

The observed wage differences between PCNPs in primary care and specialty care settings can thus be attributed to coefficient effects. Specifically, PCNPs' practice independence was a significant factor contributing to these effects. Generally, PCNPs working in a job where 
they have greater levels of independence take on more risk and thus, earn higher wages. Interestingly, this relationship held for PCNPs in primary care settings but not for those in specialty care settings. This finding may be because only a small number of PCNPs reported practicing independently in specialty care settings, which makes it difficult to detect an association between PCNP wages and their practice independence. Another explanation is that PCNPs in specialty care settings are compensated based on other factors that were not examined in this study.

Using the wage decomposition technique, this study not only examined the sources of wages differences but also identified both non-modifiable and modifiable factors that may be useful to managers of primary care organizations and policy makers. The non-modifiable factors may include PCNPs' demographic characteristics. For example, we found that female PCNPs earned less than male PCNPs holding other factors constant; and this result is consistent with previous studies (Greene, El-Banna, Briggs, \& Park, 2017; Jones \& Gates, 2004; Kalist, 2002; Muench, Sindelar, Busch, \& Buerhaus, 2015). Although gender is generally non-modifiable, these results may still suggest that managers and policy makers examine their pay structures to eliminate gender-based wage differences.

We also found some factors that potentially could be modified by policy makers at the practice, system and public policy levels. First, since we found that PCNPs who practiced independently earned higher wages than those who were supervised by a physician, policy-makers should consider whether a change in PCNP practice independence, and a potential wage increase, would help address the shortage of providers in primary care settings (Poghosyan, Liu, Shang, \& D'Aunno, 2015). Second, our results indicate that PCNPs working in rural areas earned less than those working in urban areas, a finding which is in contrast to wages for primary care physicians, in which case those who work in rural areas on average earn more than those working in urban areas (Medicare Payment Advisory Commission, 2012). One reason for this is that Medicare physicians receive a payment bonus of $10 \%$ if they practice in rural areas (Centers for Medicare and Medicaid Services, 2014). Thus, policy makers and managers in rural, primary care settings should consider providing such bonus payments and other incentives to attract PCNPs to practice in rural communities, where nurses often serve as the main providers of care (Josiah Macy Jr. Foundation, 2016). Third, this study found that PCNPs in primary care settings who planned to leave their jobs earned less than their counterparts in specialty care settings. If policy-makers wish to retain PCNPs in primary care settings, actions are needed to change payment policies for PCNPs.

The findings presented in Figure 1 show that regardless of setting, PCNPs' peak wages were only $16.6 \%$ higher than entry-level wages, which may indicate wage compression in the PCNP labor market. Wage compression refers to a phenomenon whereby small differences between individuals' peak wages and entry-level wages result in the underemployment of experienced and productive workers (Pierce, Freund, Luikart, \& Fondren, 1991).
Wage compression, a long-standing problem in nursing, is due to the lack of financial recognition for experience and productivity and is significantly associated with nurses' job satisfaction and retention (Greipp, 2003). Others have noted that $\mathrm{RN}$ salaries are is likely to increase by less than $69 \%$ throughout their career, compared with 109\% for accountants and 184\% for engineers (Evans \& Carlson, 1992; Lynn \& Redman, 2006). It may be even worse in the PCNP workforce because PCNP wages had increased less than the $27 \%$ observed for nurses in general (Jones \& Gates, 2004). Nurses may be more likely to leave their position or even leave the profession altogether if they see limited opportunities for wage increases during their career (Nooney, Unruh, \& Yore, 2010). Thus, solving wage compression may help increasing the returns to PCNPs' investments on their human capital, recognizing PCNPs' productivity and further maintain their employment in primary care settings.

There are other potentially modifiable factors that were not captured in this analysis. First, PCNPs in specialty care settings are more likely than those in primary care settings to work on a night or late shift or have to take call and thus, earn higher wages (Schumacher \& Hirsch, 1997). Managers of primary care practices may review their payment structure and improve PCNPs' compensations for working overtime. Also, under the Medicare claims payment structure, PCNPs who work in hospitals are usually paid a fixed salary, but PCNPs who work in physician offices are reimbursed at $85 \%$ to $100 \%$ of physician fees (Chapman, Wides, \& Spetz, 2010). Although little is known about whether PCNPs working in primary care settings earn less under such a payment system, the findings suggest that PCNP wages are influenced by payment policies. Examining how the payment structure of the third-party payer affects PCNP wages may help narrow the wage difference between primary care and specialty care settings.

Moreover, PCNPs who work in specialty care settings are typically supervised by a specialist and may earn more than those working in primary care settings who are supervised by a primary care physician, because specialists, on average, earn more than primary care physicians and may pay PCNPs more. Previous studies have documented that physicians working in primary care settings earn lower wages than those working in specialty care settings (Shih \& Konrad, 2007; Simon \& Born, 1996). Therefore, the wage differences between working in primary care and specialty care are not unique to nursing per se, but also to physicians. An important policy consideration is therefore to narrow the wage gap between specialist and primary care physicians, which may, in turn, eliminate some of the wage differences between NPs working in specialty versus primary care settings.

The results of this study should be interpreted in light of certain limitations. Using self-reported survey data may affect the accuracy of results, as variables in the wage model may contain measurement error. For example, measuring years of experience using the survey year minus the year when PCNPs received their NP education may not accurately reflect PCNPs' years of experience. 
Also, the analytic methods of modeling PCNP wages may be problematic due to potential model specification error. For example, NP wages may be influenced by receiving extra pay for shiftwork, or for working fulltime versus part-time on their position, but these variables were not included in the 2012 NSSNP.

Also, because NSSNP data were cross-sectional and gathered in 2011, the results of this study reflect PCNP wages at only one point in time, and do not reflect any wage changes that may have occurred subsequently. Additionally, we do not know whether the wage differences for PCNPs in primary care and specialty care settings observed in this study have changed over time.

Numerous policy changes have occurred since the implementation of the Consensus Model for Advanced Practice Registered Nurse (APRN) in 2008, which was implemented to clarify the four areas of APRN licensure, accreditation, certification, and education (National Council of State Boards of Nursing, 2008). A subsequent analysis of how this policy change has impacted NP wages is warranted, if and when data from future surveys are available. Despite these concerns, this dataset was the most currently available dataset representing the NP workforce at the time this study was conducted. Therefore, this paper represents an important step in describing PCNP wages, examining the setting-based PCNP wage differences, and attempting to explain why these differences may exist.

\section{Conclusions}

This study reported that PCNPs working in primary care settings earned, on average, considerably less than PCNPs working in specialty care settings. These wage differences were not fully explained by PCNPs' socio-demographic, human capital, and employment characteristics, but were largely due to unexplained factors. These differences may instead reflect the different working environments and payment policies between primary care and specialty care settings. Future research is needed to explore these factors.

\section{Acknowledgement}

We thank the National Center for Health Workforce Analysis, Health Resources and Services Administration, US Department of Health and Human Services for access to the National Sample Survey of Nurse Practitioners.

\section{R E F E R E N C E S}

Becker, G. S. (1962). Investment in human capital: A theoretical analysis. The Journal of Political Economy, 70, 9-49.
Becker, G. S. (2009). Human capital: A theoretical and empirical analysis, with special reference to education. University of Chicago Press, Chicago, IL.

Becker, G. S. (2010). The economics of discrimination. University of Chicago Press, Chicago, IL.

Bodenheimer, T., \& Bauer, L. (2016). Rethinking the Primary Care Workforce - An Expanded Role for Nurses. N Engl J Med, 375(11), 1015-1017, doi:10.1056/ NEJMp1606869.

Budd, G., Wolf, A., \& Haas, R. (2015). Addressing the primary care workforce: A study of nurse practitioner students' plans after graduation. The Journal of nursing education, 54(3), 130-136.

Centers for Medicare and Medicaid Services. (2014). Physician Bonuses. Retrieved from https://www.cms.gov/ Medicare/Medicare-Fee-for-Service-Payment/HPSAP SAPhysicianBonuses/.

Chapman, S. A., Wides, C. D., \& Spetz, J. (2010). Payment Regulations for Advanced Practice Nurses: Implications for Primary Care. Policy, Politics, \& Nursing Practice, 11(2), 89-98, doi:10.1177/1527154410382458.

Chattopadhyay, A., Zangaro, G. A., \& White, K. M. (2015). Practice Patterns and Characteristics of Nurse Practitioners in the United States: Results From the 2012 National Sample Survey of Nurse Practitioners. The Journal for Nurse Practitioners, 11(2), 170-177.

Coomer, N. M. (2013). Historical data indicates a wage premium for black registered nurses. Nurs Econ, 31(5), 254259.

Cotton, J. (1988). On the decomposition of wage differentials. The review of economics and statistics, 70, 236-243.

Currie, J., \& Madrian, B. C. (1999). Health, health insurance and the labor market. Handbook of labor economics, 3 , 3309-3416.

De Milt, D. G., Fitzpatrick, J. J., \& Sister Rita, M. (2011). Nurse practitioners' job satisfaction and intent to leave current positions, the nursing profession, and the nurse practitioner role as a direct care provider. J Am Acad Nurse Pract, 23(1), 42-50, doi:10.1111/j.17457599.2010.00570.x.

Ehrenberg, R. G., \& Smith, R. S. (2010). Modern labor economics: Theory and Policy. Prentice Hall, Upper Saddle River, NJ.

Evans, S. A., \& Carlson, R. (1992). Nurse-physician collaboration: Solving the nursing shortage crisis. Journal of the American College of Cardiology, 20(7), 1669-1673.

Goolsby, M. J. (2006). 2004 AANP National Nurse Practitioner Sample Survey, part III: NP income and benefits. J Am Acad Nurse Pract, 18(1), 2-5, doi:10.1111/j.17457599.2005.00094.x.

Goolsby, M. J. (2009). 2008 AANP National NP Compensation Survey. J Am Acad Nurse Pract, 21(3), 186-188, doi:10.1111/j.1745-7599.2009.00400.x.

Greene, J., El-Banna, M. M., Briggs, L. A., \& Park, J. (2017). Gender differences in nurse practitioner salaries. J Am Assoc Nurse Pract, 29(11), 667-672, doi:10.1002/23276924.12512.

Greipp, M. E. (2003). Salary compression: Its effect on nurse recruitment and retention. Journal of Nursing Administration, 33(6), 321-323.

Heisler, E. J., \& Sarata, A. K. (2011). physician supply and the patient protection and affordable care act. Retrieved from

Holtmann, A. G., \& Idson, T. L. (1993). Wage determination of registered nurses in proprietary and nonprofit nursing homes. Journal of Human resources, 28, 55-79.

Jones, C. B., \& Gates, M. (2004). Gender-based wage differentials in a predominantly female profession: Observations from nursing. Economics of Education Review, 23(6), 615-631. 
Josiah Macy Jr. Foundation. (2016). Registered Nurses: Partners in Transforming Primary Care: Recommendations from the Macy Foundation Conference on Preparing Registered Nurses for Enhanced Roles in Primary Care. Atlanta, GA.

Kalist, D. E. (2002). The gender earnings gap in the RN labor market. Nursing economic\$, 20(4), 155-162.

Keough, V. A., Stevenson, A., Martinovich, Z., Young, R., \& Tanabe, P. (2011). Nurse practitioner certification and practice settings: Implications for education and practice. J Nurs Scholarsh, 43(2), 195-202, doi:10.1111/j.15475069.2011.01395.x.

Kiker, B. F. (1966). The historical roots of the concept of human capital. The Journal of Political Economy, 74, 481-499.

Lehrer, E. L., White, W. D., \& Young, W. B. (1991). The three avenues to a registered nurse license: A comparative analysis. Journal of Human resources, 26, 362-379.

Lynn, M. R., \& Redman, R. W. (2006). Staff nurses and their solutions to the nursing shortage. West J Nurs Res, 28(6), 678-693.

McGregory, R. C. Jr (2013). An Analysis of Black-White Wage Differences in Nursing: Wage Gap or Wage Premium. The Review of Black Political Economy, 40(1), 31-37.

McGregory, R. C., Niederjohn, M. S., \& Peoples, J. (2009). Do part-time/full-time compensation differentials for nurses vary between the private and public sector. Applied Economics, 41(4), 537-546.

Medicare Payment Advisory Commission. (2012). Report to the Congress: Medicare Payment Policy Retrieved from.

Mincer, J. A. (1958). Investment in human capital and personal income distribution. The Journal of Political Economy, 66, 281-302.

Mincer, J. A. (1974). Schooling, experience, and earnings. National Brureau of Economic Research Books, Cambridge, MA.

Muench, U., Sindelar, J., Busch, S. H., \& Buerhaus, P. I. (2015). Salary differences between male and female registered nurses in the United States. Jama, 313(12), 1265-1267, doi:10.1001/jama.2015.1487.

National Council of State Boards of Nursing. (2008). Consensus model for APRN regulation: Licensure, accreditation, certification \& education.

Nooney, J. G., Unruh, L., \& Yore, M. M. (2010). Should I stay or should I go? Career change and labor force separation among registered nurses in the US. Social Science \& Medicine, 70(12), 1874-1881.

Oaxaca, R. (1973). Male-female wage differentials in urban labor markets. International economic review, 14, 693-709.

Pasaron, R. (2013). Nurse practitioner job satisfaction: Looking for successful outcomes. J Clin Nurs, 22(17-18), 2593-2604, doi:10.1111/j.1365-2702.2012.04331.x.

Petterson, S. M., Phillips, R. L. Jr., Bazemore, A. W., Burke, T. B., \& Koinis, G. T. (2013). Relying on NPs and PAs does not avoid the need for policy solutions for primary care. Am Fam Physician, 88(4), 230.

Pierce, S. F., Freund, C. M., Luikart, C., \& Fondren, L. (1991) Nurses Employed in Nonnursing Fields: Is Nursing Losing Its Best and Brightest. Journal of Nursing Administration, 21(6), 29-34.

Poghosyan, L., Liu, J., Shang, J., \& D’Aunno, T. (2017). Practice environments and job satisfaction and turnover intentions of nurse practitioners: Implications for primary care workforce capacity. Health Care Manage Rev, 42(2), 162-171, doi:10.1097/hmr.0000000000000094.

Reimers, C. W. (1983). Labor market discrimination against Hispanic and black men. The review of economics and statistics, 65, 570-579.

Schultz, T. W. (1961). Investment in human capital. The American economic review, 51, 1-17.

Schumacher, E. J., \& Hirsch, B. T. (1997). Compensating differentials and unmeasured ability in the labor market for nurses: Why do hospitals pay more. Industrial and Labor Relations Review, 50, 557-579.

Shih, Y. C., \& Konrad, T. R. (2007). Factors associated with the income distribution of full-time physicians: A quantile regression approach. Health Serv Res, 42(5), 1895-1925, doi:10.1111/j.1475-6773.2006.00690.x.

Simon, C. J., \& Born, P. H. (1996). Physician earnings in a changing managed care environment. Health Affairs, 15 (3), 124-133, doi:10.1377/hlthaff.15.3.124.

Spetz, J. (2002). The value of education in a licensed profession: The choice of associate or baccalaureate degrees in nursing. Economics of Education Review, 21(1), 73-85.

Spetz, J., Fraher, E., Li, Y., \& Bates, T. (2015). How Many Nurse Practitioners Provide Primary Care? It Depends On How You Count Them. Medical Care Research and Review, 72(3), 359-75 1077558715579868

U. S. Department of Health and Human Services. (2016). State-Level Projections of Supply and Demand for Primary Care Practitioners: 2013-2025. Retrieved from Rockville, Maryland.:

U.S. Department of Health and Human Services. (2014). The 2012 National Sample Survey of Nurse Practitioners: Variables Definitions Document. Retrieved from Rockville, Maryland:

Walani, S. R. (2013). Earnings of the Internationally Educated Nurses in the U.S. Labor Market. Nursing research, 62(3), 169-177.

Wilder, V., Dodoo, M. S., Phillips, R. L. Jr, Teevan, B., Bazemore, A. W., Petterson, S. M., \& Xierali, I. (2010). Income disparities shape medical student specialty choice. Am Fam Physician, 82(6), 601.

Willis, R. J. (1985). Wage determinants: A survey and reinterpretation of human capital earnings functions. Economics Research Center/NORC, 1, 525-602. 